\title{
INTELLECTUAL PROPERTY INFRINGEMENT BY FOREIGN FIRMS: IMPORT PROTECTION THROUGH THE ITC OR COURT
}

\author{
James A. Brander \\ Barbara J. Spencer \\ Working Paper 28496 \\ http://www.nber.org/papers/w28496
NATIONAL BUREAU OF ECONOMIC RESEARCH
1050 Massachusetts Avenue
Cambridge, MA 02138
February 2021

We thank Yoko Sakamoto and Steffan Ziss for very valuable discussant's comments on the paper. We also thank Vanessa Alviarez, Ed Egan, Taiji Furusawa, and Keith Head. We are grateful for financial support from SSHRC grant 435-2017-0627. The views expressed herein are those of the authors and do not necessarily reflect the views of the National Bureau of Economic Research.

NBER working papers are circulated for discussion and comment purposes. They have not been peer-reviewed or been subject to the review by the NBER Board of Directors that accompanies official NBER publications.

(C) 2021 by James A. Brander and Barbara J. Spencer. All rights reserved. Short sections of text, not to exceed two paragraphs, may be quoted without explicit permission provided that full credit, including $\odot$ notice, is given to the source. 
Intellectual Property Infringement by Foreign Firms: Import Protection through the ITC or

Court

James A. Brander and Barbara J. Spencer

NBER Working Paper No. 28496

February 2021

JEL No. C70,F12,F13,K41,O34

\section{ABSTRACT}

This paper examines intellectual property litigation as a method of protection from patentinfringing imports. Claims against patent-infringing imports entering the United States may be filed before the International Trade Commission (ITC) or in district court. The ITC applies injunctions (import prohibitions) that would seem to provide more protection from infringing imports than the standard license fee remedy in court. Settlements prior to legal adjudication are common in both venues. Using a model with Nash bargaining and Cournot competition, we show that an ITC filing may restrict imports by less than in court. This result tends to apply if product differentiation is high and the size of the patented cost-reducing innovation is large.

James A. Brander

University of British Columbia

Sauder School of Business

2053 Main Mall

Vancouver, B.C. V6T 1Z2 CANADA

brander@sauder.ubc.ca

Barbara J. Spencer

University of British Columbia

Sauder School of Business

2053 Main Mall

Vancouver, BC V6T $1 Z 2$

CANADA

and NBER

barbara.spencer@sauder.ubc.ca 


\section{Introduction}

There is increasing concern in the United States about intellectual property (IP) theft by foreign parties, both foreign firms and foreign governments. Sometimes the federal government becomes directly involved but more commonly legal action is left to the IP owner. Large technology-intensive companies such as Apple and Google are engaged in IP litigation on an essentially constant basis. This paper addresses the implications of IP litigation for protection from patent-infringing imports.

When domestic IP is infringed by imports, two major types of relief are typically available: fee-based relief or injunctive relief. In the United States, the type of relief depends mainly on where the IP claim is filed. Claims may be filed in federal district court, where relief is normally in the form of license fees. ${ }^{1}$ Alternatively, claims against imports may be filed before the "quasi-judicial” International Trade Commission (ITC). The remedy used by the ITC is an injunction that prohibits imports using the infringed IP. The ITC has become an important venue for IP cases, which are now arguably more important in economic terms than other types of ITCadministered trade policy such as anti-dumping duties and countervailing duties.

On the surface, the ITC seems to provide more import protection than the courts. With a court-imposed license fee, imports can still be sold in the domestic market, whereas injunctive relief at the ITC normally excludes imports entirely. However, in both the ITC and court, negotiation between the parties is important and many cases are settled before final legal adjudication. And, in both forums, license fees are the normal outcome of negotiated settlements. Such settlements have important implications for the level of import protection.

We develop the implications of an ITC versus a court filing for protection from patentinfringing imports using a standard differentiated-product duopoly model with Cournot competition. Nash bargaining is used to model the potential for negotiated settlements. We address two main research questions. First, we ask if and when the ITC would provide more import protection than the courts in the sense that an ITC case results in lower import levels. The

\footnotetext{
1 The preference for fee-based relief in district court has been in place since a landmark unanimous U.S. Supreme Court decision, eBay Inc. v. MercExchange, 547 U.S. 388 (2006), specifying that courts should use injunctions only when license fees or other monetary awards are insufficient.
} 
answer will help explain why many firms seeking redress from IP infringement choose to file in court, given the more extreme remedy available at the ITC. Second, we seek to explain the incentives underlying the common use of negotiated settlements.

We consider the case in which the infringed innovation reduces marginal cost and adjudication by the court takes the form of a per-unit license fee or royalty applied to infringing imports. In our base model, the default royalty imposed by the court equals the value of the innovation as measured by its effect in reducing the foreign firm's marginal cost. Also, firms engage in Nash bargaining over a royalty to reach a settlement. Our choice of the default royalty and the effects of fixed license fees in Nash bargaining are considered in an extension section. However, as noted by Kamien (2002, p. 345) and others, some form of output-based payment or royalty is much more common than fixed license fees. The main reasons include risk aversion, liquidity constraints, and informational asymmetries.

The answers to our research questions depend on two primary considerations. One consideration is the degree of differentiation between domestic and imported products. The other is the "size" or value of the infringed innovation as measured by whether the innovation is "incremental" or "drastic" in the sense of Arrow (1962). The domestic firm faces two conflicting incentives, namely to reduce competition from infringing imports and earn royalties from those same imports. ${ }^{2}$ If the products are perfect substitutes then the competitive effect dominates, as the best possible outcome for the domestic firm is to be a monopoly. But if products are even slightly differentiated, we show that the outcome at the ITC is a settlement with a royalty that allows some imports. For court cases, the outcome for almost all incremental innovations is an adjudicated royalty equal to the value of the innovation. For drastic innovations, the royalty negotiated in either venue is less than the value of the innovation and therefore provides the foreign firm with a net benefit from infringement.

Greater product differentiation always reduces the negotiated royalty in ITC cases and hence reduces the import protection provided by the ITC. For small incremental innovations, an ITC filing does result in greater protection from imports than in court. However, for larger incremental innovations, sufficiently high product differentiation reverses this result - court

\footnotetext{
${ }^{2}$ We refer to the "domestic firm" and the "foreign firm" although what matters for the ITC is where the product is produced, not the headquarters location of the producing company.
} 
cases provide a higher level of protection than ITC cases, even thought the ITC uses import prohibitions. For drastic innovations, it is never the case that a filing at the ITC provides more protection from imports than the courts.

The current paper builds on Brander and Spencer (2021), who also compare injunctive with fee-based relief for patent infringement allowing for settlements based on Nash bargaining. The setting in that paper is purely domestic as a monopoly firm infringes a patent held by a patent assertion entity (PAE). The PAE produces no output so the infringing firm has no competitive effect. Product differentiation does not arise.

Section 2 contains a short literature review. Section 3 presents the basic model structure, section 4 describes the final-stage output game and section 5 concerns homogeneous products. For differentiated products, section 6 addresses the Nash bargaining outcomes from an ITC or court filing. Section 7 examines the decision by the domestic firm as to where to file its claim. Section 8 concerns extensions and generalizations. Section 9 contains concluding remarks.

\section{Literature Review}

ITC protection of U.S. intellectual property through injunctive relief is a form of administered trade policy, as are the more extensively studied anti-dumping and countervailing duty policies. Blonigen and Prusa (2019) provide a recent overview of the literature on antidumping policy, and Irwin (2005) describes the history of anti-dumping policy. Countervailing duties are often studied in conjunction with anti-dumping duties as in, for example, Gallaway, Blonigen, and Flynn (1999) and Rovengo (2013). Prusa (1992) uses Nash bargaining to model negotiations in anti-dumping cases, and we take a similar approach to IP filings in the ITC or courts based on patent infringements by foreign firms.

Although the role of intellectual property in international trade has received significant attention (such as Maskus and Penubarti, 1995, Chen, Ishikawa, and Yu, 2004, McCalman, 2005, Qiu and Yu, 2010, and Bond and Saggi, 2020), we have found only a few papers that address administered protection based on intellectual property. Specifically, Aoki and Prusa (1992) focus on R\&D incentives arising from administered IP protection and Schwarz (1991) provides some explicit calculations illustrating the cost to consumers from the exclusion of imports based on patent infringement. Mutti and Yeung (1996) estimate various empirical effects of IP-based ITC 
actions, Co (2004) assesses the value of the patents underlying IP-based ITC cases, and Brander (2007) considers strategic trade policy incentives for IP protection.

Our analysis is related to the large literature on patent policy, patent licensing, and patent litigation. Gallini (2002) reviews U.S. patent reforms and the major principles underlying patent policy. Kamien (1992) summarizes major early contributions to the theory of patent licensing. The Nash bargaining solution has been used to study patent licensing and patent litigation by several authors, including Shapiro (2010), Kishimoto and Muto (2012), Kishimoto (2020), Crampes and Langiner (2002) and Brander and Spencer (2021). Daughety and Reinganum (2012) provide an overview of the economic literature on litigation and settlement of disputes.

\section{Modelling Preliminaries}

A domestic firm produces good $\mathrm{x}$ and a foreign firm produces and exports good $\mathrm{y}$ to the domestic country. The demand for the two substitute goods derives from the following symmetric quadratic utility function where $\mathrm{M}$ represents consumption of a numeraire good.

$$
U=a(x+y)-\left(x^{2}+y^{2}\right) / 2-s x y+M
$$

The goods are substitutes, so $s$ must be positive and cannot exceed 1: $0<s \leq 1$. (The goods are unrelated if $s=0$ and complements if $s<0$.) Utility function (1) implies that the slope of each firm's demand function is normalized to be -1 . Therefore, letting $p^{\mathrm{x}}$ and $p^{\mathrm{y}}$ denote the prices of goods $\mathrm{x}$ and $\mathrm{y}$, the inverse demand functions are:

$$
p^{x}=a-x-s y ; p^{y}=a-y-s x
$$

The domestic firm owns a patent on a cost-reducing innovation that it uses for its own production. The foreign firm violates the patent by using the innovation without permission. Without the technology embodied in the patent, the marginal cost of production for both firms would be a constant, $c$. Letting $v$ denote the value of the patented innovation in reducing per-unit cost, both firms have a marginal cost of production of $c-v$. We refer to $v$ as the "value of the innovation". The following regularity conditions apply.

Regularity Conditions: i) $c-v \geq 0$ (marginal cost cannot be negative)

ii) $v>0$ (the patented innovation has value)

iii) $a>c$ (maximum willingness to pay exceeds marginal cost) 
If ii) is not satisfied no infringement cases would be filed and we do not consider that case further. As $a-c>0$ from iii), production would take place in the absence of the innovation.

The value of the innovation, $v$, is assumed to be known by both firms, by the ITC, and by the court. Therefore, if the case goes to legal adjudication in the ITC, it follows from $v>0$ (regularity condition ii) that an injunction will prohibit imports. In court, a default royalty of $v$ is imposed if there is adjudication, just offsetting the per-unit cost reduction due to the innovation. In either venue, the firms attempt to reach a settlement through Nash bargaining over a royalty.

In section 8 concerning extensions and generalizations, we consider the effects of introducing uncertainty over the ITC's decision and the court's decision. We also consider an alternative default royalty to be imposed by the court and argue that a default royalty of $v$ is broadly consistent with the case record. In addition, we show that our main results are robust, at least qualitatively, to Nash bargaining over a fixed fee rather than a royalty.

To examine the effect of the size of the innovation, following Arrow (1962), we adopt the following definitions.

Definitions: i) if $v<a-c$, the innovation is incremental.

ii) if $v=a-c$, the innovation is intermediate.

iii) if $v>a-c$, the innovation is drastic.

Our analysis presumes that the foreign firm has previously incorporated the infringing technology of value $v$ in its current production infrastructure. Accordingly, use of the technology is "sunk" for at least some period of time and the domestic firm cannot undo it over the time horizon of the game analyzed here. In practice, firms that receive adverse patent infringement rulings will sometimes restructure production to avoid infringing the patent in question. But such restructuring, even if feasible, is costly and time-consuming and is outside the scope of the current analysis. The degree of product differentiation is also pre-determined, as is the decision of the domestic firm to file an infringement claim.

Our overall equilibrium concept is the sequentially rational equilibrium in the following three-stage game:

Stage 1: The domestic firm decides whether to file a claim before the ITC or in court. 
Stage 2: The two firms engage in Nash bargaining over a royalty. If they settle, that settlement determines the royalty. If they do not settle, the outcome (royalty of $v$ in court or ITC injunction) is determined by legal adjudication.

Stage 3: Firms play a Cournot output game unless imports are excluded by injunctive relief, in which case the domestic firm has a domestic monopoly. The foreign firm pays the royalties determined in stage 2 to the domestic firm.

\section{Stage 3 -- Output Determination}

Letting $r$ denote the value of a royalty, the profit of each firm is made up of the standard profit from production plus the effect of the transfer of royalty revenue, $r y$, from the foreign to the domestic firm. Letting $m \equiv a-(c-v)>0$ denote the difference between the demand intercept, $a$, and the net marginal cost, $c-v$ and, using (2), domestic and foreign profits are respectively given by

$$
\begin{aligned}
& \pi=\left[p^{\mathrm{x}}-(c-v)\right] x+r y=(m-x-s y) x+r y \\
& \pi^{\mathrm{f}}=\left[p^{\mathrm{y}}-(c-v)\right] y-r y=(m-r-s x-y) y
\end{aligned}
$$

If both firms are in the market, they act as Cournot duopolists. Each firm chooses its output to maximize its profit in stage 3, taking the output of the other firm and also the royalty $r$ determined in stage 2 as given. The degree of substitutability, s, and the value, $v$, of the patented innovation are exogenous variables. From (3), the first order conditions for profit maximization by the domestic and foreign firms are

$$
\begin{aligned}
& \partial \pi / \partial x=-2 x-s y+m=0 \\
& \partial \pi^{f} / \partial y=-s x-2 y+m-r=0
\end{aligned}
$$

It follows immediately from (4) that corresponding second order conditions are satisfied. Solving the equations in (4) for $x$ and $y$, equilibrium outputs can be expressed as

$$
\begin{aligned}
& x(r ; s)=((2-s) m+s r) /\left(4-s^{2}\right) ; \\
& y(r ; s)=((2-s) m-2 r) /\left(4-s^{2}\right)
\end{aligned}
$$

The equilibrium profits of the domestic and foreign firm are as follows.

$$
\pi(r)=(x(r))^{2}+r y(r) ; \pi^{\mathrm{f}}(r)=(y(r))^{2}
$$


The domestic firm's profit is the sum of its profit from good $x$ and royalty revenue, whereas the foreign firm's profit includes its royalty payment as a component of its marginal cost.

If the ITC imposes an injunction against imports or if a royalty is so high that it prevents imports, then the domestic firm has a monopoly. Referring to the smallest royalty that prevents imports, denoted by $r^{P}(s)$, as the prohibitive royalty, it follows, setting $y(r ; s)=0$ in (5), that

$$
r^{P}(s)=(2-s) m / 2
$$

From (7) and $m \equiv a-c+v$, the prohibitive royalty is increased by greater product differentiation (a smaller $s$ ) and by a larger value $v$ of the innovation. As the domestic firm would never pay the foreign firm, without loss of generality we restrict attention to royalties satisfying $r \in\left[0, r^{P}(s)\right]$.

\section{Homogenous Products}

With homogeneous products, the best possible outcome for the domestic firm is for imports to be prohibited so that it gains a monopoly of the domestic market. Letting $r^{*}(s)$ represent the domestic firm's profit-maximizing royalty, it follows using (5), (6) and (7), that with homogenous products ( $s=1)$, domestic profit is maximized at the prohibitive royalty: ${ }^{3}$

$$
r^{*}(1)=r^{P}(1)=m / 2=(a-c+v) / 2
$$

For ITC cases, the domestic firm achieves its maximum profit by letting the case go to legal adjudication, as the ITC will prohibit infringing imports. Therefore, no settlement is possible. In court, the two firms have diametrically opposed preferences as the foreign firm always prefers a lower royalty while the domestic firm always prefers a higher royalty. No settlement is possible and the court imposes a royalty of $v$. Imports occur if and only if $v$ is less than the prohibitive royalty, which, as can be seen from (8), applies if and only if the innovation is incremental. Proposition 1 summarizes these results.

Proposition 1: ITC and court outcomes with homogeneous products

With homogeneous products:

${ }^{3}$ For $s=1$, from (5) and (6), we obtain $\pi(r)=(m+r)^{2} / 9+r(m-2 r) / 3, \pi^{\prime}(r)=5 m-10 r$ and $\pi^{\prime \prime}(r)$ $<0$. Maximizing $\pi(r)$ subject to $r \leq r^{\mathrm{P}}(1)=m / 2$ (see (7)), we obtain $\pi^{\prime}(r)=0$ at $r=m / 2$ and hence $r^{*}(1)=r^{\mathrm{P}}(1)=m / 2$ as in (8). 
i) An ITC filing always goes to legal adjudication, so imports are prohibited.

ii) A court filing always goes to legal adjudication. Imports are eliminated if the innovation is drastic or intermediate and are positive if the innovation is incremental.

iii) The domestic firm will choose to file in the ITC.

\section{Stage 2 - Nash bargaining with differentiated products}

\subsection{Incentives of the Domestic firm with differentiated products}

To understand the incentives underlying Nash bargaining for ITC or court cases with differentiated products, we first examine the domestic firm's profit maximizing royalty. As shown in (A4) of the Appendix,

$$
r^{*}(s)=\left(4+2 s-s^{2}\right)(2-s) m / 2\left(8-3 s^{2}\right)
$$

Proposition 2 describes the properties of $r^{*}(s)$, including a comparison with the royalty that maximizes royalty revenue, denoted $r^{\mathrm{R}}(s)$. The proofs of Proposition 2 and all subsequent propositions are in the Appendix.

Proposition 2: The domestic firm's profit-maximizing royalty

i) For any given $s \in(0,1)$, domestic profit is maximized at a unique royalty, $r^{*}(s)$, that exceeds the level that maximizes royalty revenue, but does not prevent imports: $r^{\mathrm{R}}(s)<r^{*}(s)<r^{\mathrm{P}}(s)$.

ii) The profit-maximizing royalty, $r^{*}(s)$ for $s \in(0,1)$, approaches $m / 2$ as $s$ approaches either limit ( 0 or 1 ) and reaches a unique minimum at an interior value of $s$, denoted $s^{\theta}$.

Product differentiation fundamentally changes the incentives of the domestic firm towards imports. As shown in Proposition 2(i), any degree of product differentiation reduces the profit-maximizing royalty, $r^{*}(s)$, below the prohibitive level. With the reduction in the intensity of competition, the domestic firm is always better off collecting some royalty revenue than by excluding imports so as to become a monopolist. The domestic firm prefers a royalty that exceeds $r^{\mathrm{R}}(s)$ because the reduction in imports from a small increase in $r$ above $r^{\mathrm{R}}(s)$ increases its profit from production by more than enough to offset the loss of royalty revenue.

From Proposition 2(ii), $r^{*}(s)$ is U-shaped in $s$. If products were completely independent ( $s$ $=0$ ), the domestic firm would want to charge $r^{\mathrm{R}}(0)=m / 2$ so as to maximize royalty revenue. Greater substitutability of products reduces the revenue-maximizing royalty, $r^{\mathrm{R}}(s)$, because a 
reduction in variety reduces consumer demand and imports also become more responsive to the royalty. If $s$ is small, $r^{*}(s)$ also falls. However, as the products become closer substitutes, the gap between $r^{*}(s)$ and $r^{\mathrm{R}}(s)$ increases, reflecting the increasing efforts by the domestic firm to reduce imports in the face of greater competition. As a result, $r^{*}(\mathrm{~s})$ reaches a minimum and then rises in accordance with the U-shaped pattern until at $s=1$, the royalty $r^{*}(1)=m / 2$ becomes prohibitive.

As we show in Proposition 3, the domestic firm may prefer a royalty either above or below the value, $v$, of the innovation, depending on the size of the innovation.

Proposition 3: Innovation value and the domestic firm's profit-maximizing royalty With differentiated products:

i) If the innovation is incremental $(v<a-c)$, the domestic firm's profit-maximizing royalty equals or exceeds the value of the innovation $\left(r^{*}(s) \geq v\right)$ for almost all values of $v$, specifically for $v \leq 0.9559(a-c)$. If $0.9559(a-c)<v<a-c$, then the comparison between $r^{*}(s)$ and $v$ depends on $s$ and $v$.

ii) If the innovation is intermediate $(v=a-c)$ or drastic $(v>a-c)$, the domestic firm's profitmaximizing royalty is always less than value the innovation $\left(r^{*}(s)<v\right)$.

From Proposition 3, the domestic firm's profit-maximizing royalty, $r^{*}(s)$, exceeds $v$ for over 95\% of the range for incremental innovations. This result arises from the fact that the Ushape of $r^{*}(s)$ as $s$ varies is very shallow. The minimum of $r^{*}(\mathrm{~s})=0.48873 \mathrm{~m}$ (reached at $s=$ 0.7117) is not much below its maximum of $m / 2$ (see the proof of Proposition 3). For intermediate and drastic innovations, a royalty of $v$ sufficiently reduces imports and royalty revenue that the domestic firm wants to charge less than the value of the innovation.

\subsection{Nash Bargaining with Differentiated Products for ITC Cases}

Since a ruling by the ITC will provide injunctive relief that blocks imports, in Nash bargaining at the ITC, the disagreement payoff for the domestic firm is its monopoly profit. Evaluating profit at the prohibitive royalty, we express this monopoly profit as $\pi\left(r^{P}(s)\right)$. The foreign firm has a disagreement payoff of zero. We use the superscript I to identify variables associated with the ITC. Following Nash (1953), the Nash product, denoted B ${ }^{\mathrm{I}}(r)$ (B for “bargain”) is given by

$$
\mathrm{B}^{\mathrm{I}}(r)=\left(\pi(r)-\pi\left(r^{\mathrm{P}}(s)\right) \pi^{\mathrm{f}}(r)\right.
$$


The Nash bargaining solution is the royalty, denoted $r=r^{\mathrm{I}}(s)$, that maximizes $\mathrm{B}^{\mathrm{I}}(r)$ subject to $0 \leq$ $r \leq r^{\mathrm{P}}(s)$. A settlement is a Nash bargaining solution in which each firm obtains positive surplus relative to its disagreement payoff.

Proposition 4 shows that ITC cases with differentiated products always result in settlements and provides an explicit solution for the negotiated royalty. Greater product differentiation (smaller s) reduces the negotiated royalty and increases imports.

Proposition 4: Negotiated settlements at the ITC:

For ITC cases with differentiated products and Nash bargaining by firms:

i) There is always a settlement with some imports. The negotiated royalty is unique and is given by $r^{\mathrm{I}}(s) \equiv(2+3 s)(2-s) m / 2\left(8-3 s^{2}\right)$.

ii) The negotiated royalty is less than the domestic profit-maximizing royalty: $r^{\mathrm{I}}(s)<\mathrm{r}^{*}(s)$

iii) Greater product differentiation reduces the negotiated royalty and increases imports.

The proof of Proposition 4 establishes that $\mathrm{B}^{\mathrm{I}}(r)$ is strictly concave for $r \in\left(0, r^{*}(s)\right)$ and finds $r^{\mathrm{I}}(s)$, the value of $r$ that globally maximizes the Nash product. The prohibitive royalty, $r^{\mathrm{P}}(s)$, is shown to minimize $\mathrm{B}^{\mathrm{I}}(r)$, so the constraint $r \leq r^{\mathrm{P}}(s)$ is not binding and there are always some imports. From (10), the royalty, $r^{\mathrm{I}}(s)$, satisfies the first order condition:

$$
\mathrm{dB}^{\mathrm{I}}(r) / \mathrm{d} r=\left[\pi(r)-\pi\left(r^{\mathrm{P}}(s)\right] \pi^{\mathrm{f}}(r)+\pi^{\mathrm{f}}(r) \pi^{\prime}(r)=0\right.
$$

Proposition 5 examines whether royalties established though negotiation in the ITC are above or below $v$. The answer depends on the size of the innovation and the degree of substitutability between the imported and domestic product.

Proposition 5: Royalty rates and the value of innovation for ITC cases For ITC cases with differentiated products:

i) An increase in the innovation's value $v$ increases the negotiated royalty, $r^{\mathrm{I}}(s)$, but by less than the increase in $v: 0<\partial r^{\mathrm{I}}(s ; v) / \partial v<1$.

ii) For small incremental innovations defined by $v \leq(a-c) / 3$, the negotiated royalty $r^{\mathrm{I}}(s)$ strictly exceeds the value of the innovation $\left(r^{\mathrm{I}}(s)>v\right)$.

iii) For larger incremental innovations $((a-c) / 3<v<a-c)$, there exists a critical value of $s \equiv$ $\breve{s}(v) \in(0,1)$ satisfying $r^{\mathrm{I}}(\breve{s})=v$, such that $r^{\mathrm{I}}(s)<v$ if and only if the products are sufficiently 
differentiated ( $s$ is sufficiently small) that $s \in(0, \check{s}(v))$. As $v$ becomes larger, $\check{s}(v)$ increases, expanding the range of cases for which $r^{\mathrm{I}}(s)<v$ to include products that are more similar. iv) For intermediate or drastic innovations $(v \geq a-c)$, the negotiated royalty is strictly less than the value of the innovation $\left(r^{\mathrm{I}}(s)<v\right)$.

From Proposition 5, the royalty, $r^{\mathrm{I}}(s)$, negotiated at the ITC is higher for higher value innovations, but the increase is less than the increase in $v$. For small incremental innovations $(v<$ $(a-c) / 3)$, the royalty exceeds the value of the innovation. However, greater product differentiation reduces $r^{\mathrm{I}}(s)$ (Proposition 4(iii)) and for larger incremental innovations, Proposition 5 shows that sufficient product differentiation will reduce $r^{\mathrm{I}}(s)$ below $v$. For intermediate or drastic innovations $(v \geq a-c), r^{\mathrm{I}}(s)$ is always below $v$.

\subsection{Nash Bargaining with differentiated products for Court Cases}

Court cases subdivide into two categories depending on whether or not the default royalty of $v$ imposed by the court would prevent imports. For innovations large enough that the default royalty equals or exceeds the prohibitive level $\left(v \geq r^{\mathrm{P}}(s)\right)$, the court and the ITC have the same disagreement payoffs and the same Nash bargaining solution. The outcome of a case filed in court is then a settlement at the same royalty that would be negotiated at the ITC.

For innovations for which a royalty of $v$ allows imports, the disagreement payoffs in court are the strictly positive profits of the domestic and foreign firms at $r=v$. Letting the superscript $C$ identify variables associated with the court, the Nash product is:

$$
\mathrm{B}^{\mathrm{C}}(r)=(\pi(r)-\pi(v))\left(\pi^{\mathrm{f}}(r)-\pi^{\mathrm{f}}(v)\right) \text { for } v<r^{\mathrm{P}}(s)
$$

Proposition 6 sets out the results of a court filing when court adjudication allows imports. From the proof of Proposition 6, the Nash bargaining solution for court cases, denoted $r^{\mathrm{C}}(s)$, is unique and satisfies the first order condition:

$$
\mathrm{dB}^{\mathrm{C}}(r) / \mathrm{d} r=[\pi(r)-\pi(v)] \pi^{\mathrm{f} \prime}(r)+\left(\pi^{\mathrm{f}}(r)-\pi^{\mathrm{f}}(v)\right) \pi^{\prime}(r)=0
$$

Proposition 6: Settlement or adjudication in court when $v<r^{\mathrm{P}}(s)$.

For cases filed in court with differentiated products and $v<r^{\mathrm{P}}(s)$ :

i) If $v \leq r^{*}(s)$ the firms do not settle and the court adjudicates a royalty of $v$.

ii) If $v>r^{*}(s)$ there is a settlement. The firms negotiate a unique royalty, $r^{\mathrm{C}}(s)$, that exceeds zero 
and is less than the domestic profit-maximizing royalty: $0<r^{\mathrm{C}}(s)<r^{*}(s)$.

If $v \leq r^{*}(s)$, then the domestic firm will not accept less than $v$ and the court adjudicates a license fee of $v$. Conversely, if $r^{*}(s)<v<r^{\mathrm{P}}(s)$, then both firms would prefer a royalty less than what the court would impose, so a settlement is reached. It might be argued that a court would not impose a royalty that exceeds the amount that both firms prefer. However, in practice, courts are often influenced both by legal precedent and by the deterrent effect of decisions and are not guided just by the interests of the two parties. Such "high" default royalties are possible. In Section 8, we consider an extension in which the default royalty is the smaller of $v$ and the domestic firm's preferred royalty.

Proposition 7 relates the conditions under which $v<r^{\mathrm{P}}(s)$ (so outcomes in court and the ITC differ), to the magnitude of the $v$ and the degree of product differentiation.

Proposition 7: Conditions for $v<r^{\mathrm{P}}(s)$

i) For differentiated products, a royalty of $v$ allows some imports $\left(v<r^{\mathrm{P}}(s)\right)$ if:

(a) the innovation is incremental or intermediate $(v \leq a-c)$ or

(b) the innovation is drastic $(v>a-c)$ and $v \in(a-c, \gamma(a-c))$ where $\gamma \equiv(2-s) / s>1$.

ii) In the limit as products become independent ( $s$ tends to zero), a royalty of $v$ can never prevent imports. As products become more substitutable, the range of values of $v$ for which there are imports is reduced and, in the limit as $s$ tends to 1 , there are no imports for $v \geq a-c$.

\subsection{Comparing the ITC and Court Regimes}

Assuming that venue outcomes differ $\left(v<r^{\mathrm{P}}(s)\right)$, Proposition 8 addresses our central research question concerning whether the ITC regime provides more protection from imports than the court. For any given level of product differentiation, imports increase as the royalty falls. Therefore, the question of which venue provides more protection against imports is equivalent to asking which venue leads to a higher royalty. We obtain the seemingly counterintuitive result that, even though the ITC uses exclusion and the court does not, filing a claim in court provides more protection in some cases.

Proposition 8: Does the ITC or the Court provide more import protection?

With differentiated products and $v<r^{\mathrm{P}}(s)$ :

i) The ITC provides more import protection than the court if $r^{\mathrm{I}}(s)>v$. 
ii) The two venues provide equal import protection if $r^{\mathrm{I}}(s)=v$.

iii) The ITC provides less import protection than the court if the negotiated royalty for an ITC case is less than the cost-reducing value of the innovation: $r^{\mathrm{I}}(s)<v$.

Proposition 8 provides a simple condition that determines which venue provides more protection from imports. Specifically, the court venue leads to lower imports if the royalty negotiated at the ITC is less than the value of the innovation. Whenever the royalty, $r^{\mathrm{I}}(s)$, negotiated at the ITC is below $v$, it is also below the royalty, $r^{\mathrm{C}}(s)$, that would arise for a case filed in court, including cases in which $r^{\mathrm{C}}(s)<v$ due to a settlement.

The above condition relates comparative import protection to the endogenous variable $r^{\mathrm{I}}(s)$. This relationship could be useful in an empirical context as $r^{\mathrm{I}}$ is potentially observable. However, more conceptual understanding is provided by solving for relative import protection purely as a function of underlying structural (exogenous) parameters, as in Proposition 9.

Proposition 9: Innovation size and protection from imports by venue With differentiated products:

i) For small incremental innovations $(v \leq(a-c) / 3)$, the ITC provides more protection from imports than the court. A royalty of $v$ is adjudicated by the court, whereas in the ITC, the firms settle at $r=r^{\mathrm{I}}(s)$ that strictly exceeds $v$.

ii) For larger incremental innovations $((a-c) / 3<v<a-c)$, the ITC provides less protection from imports than the court if and only if the products are sufficiently differentiated that $s<\check{s}(v)$ where š satisfies $r^{\mathrm{I}}(\breve{\mathrm{s}}) \equiv v$. If $s<\breve{s}(v)$, firms settle on a royalty, $r^{\mathrm{I}}(s)$, in the ITC that is strictly less than $v$ and less than any royalty, $r^{\mathrm{C}}(s)$, negotiated in court. The higher is the value of $v$, the greater is the range of product differentiation for which the ITC provides less protection from imports than the court.

iii) For innovations that are intermediate or drastic but not so drastic that a royalty of $v$ is prohibitive $(v \in[a-c, \gamma(a-c))$ where $\gamma \equiv(2-s) / s>1)$, the ITC provides less protection from imports than the court. The firms settle on a royalty below $v$ in both venues, but the royalty is strictly lower in the ITC.

iv) For very drastic innovations $\left(v \geq r^{P}(s)\right)$, the ITC and the court provide the same protection against imports. There is a settlement in both venues and Nash bargaining in the court and the ITC yield the same royalty giving rise to the same (positive) level of imports. 
Propositions 8 and 9 show that relying on the ITC does provide greater import protection than court-based relief in some cases. The counter-intuitive outcome in which the court provides more protection is favored by greater product differentiation (lower values of $s$ ) and by values of $v$ that are quite high, but not high enough such that a royalty of $v$ would be prohibitive.

To understand these results, it is useful to recall from Proposition 3(ii) that the desire to increase royalty revenue reduces the domestic firm's profit-maximizing royalty, $r^{*}(s)$, below $v$ for intermediate and drastic innovations $(v \geq a-c)$. The foreign firm always wants a lower royalty, so in both venues, the parties settle at a royalty below $v$. The settlement is at a lower royalty in the ITC than the court, making the ITC less protective of imports because the domestic firm has a more attractive disagreement payoff relative to the foreign firm in court than in the ITC. With $a-c \leq v<r^{\mathrm{P}}(s)$, the default royalty of $v$ in court provides sufficient royalty revenue that the domestic firm's profit exceeds its monopoly profit from an ITC injunction. The foreign firm gains profit, $\pi^{\mathrm{f}}(v)$, from adjudication in court and zero profit in the ITC, but $\pi^{\mathrm{f}}(v)$ is sufficiently small due to the high marginal cost from the royalty that the domestic firm has a relative advantage in court. ${ }^{4}$

In contrast, for small incremental innovations with $v \leq(a-c) / 3$, the domestic profitmaximizing licensee fee exceeds $v$ (Propositions 3(i)). In court, the domestic firm will choose to accept adjudication of a royalty of $v$ rather than negotiate. Negotiation in the ITC results in a royalty that exceeds $v$ (Proposition 5(ii)) making the ITC more protective than the court in this case. For the remaining (i.e. larger) incremental innovations, which venue provides more protection (lower imports) depends on the extent of product differentiation.

\section{Stage 1 - Where to File?}

The first stage is relatively straightforward as only one firm acts. Specifically, the domestic firm decides where to file its patent infringement complaint. In practice, firms are allowed to file in both venues, which is fairly common. Allowing the possibility of filing in both venues raises a variety of interesting issues that relate largely to uncertainty as filing in both venues is a form of diversification for the plaintiff firm. However, many firms choose to file in

\footnotetext{
${ }^{4}$ For $a-c \leq v<r^{\mathrm{P}}(s)$ and $s \in(0,1)$, it can be shown using (A10) of the appendix, (6) and (5) that
} $\pi(v)-\pi\left(r^{\mathrm{P}}(s)\right)-\pi^{\mathrm{f}}(v) \geq v y(v)(1-s) / 2>0$. 
only one venue. In our setting there is no uncertainty and no advantage to the domestic firm from filing in more than one venue. As shown in Proposition 10, if the venues $\operatorname{differ}\left(v<r^{P}(s)\right)$, the domestic firm always chooses the venue with the higher royalty, which is the venue with the higher level of protection as set out in Proposition 9.

\section{Proposition 10: Choosing where to file}

For $v<r^{P}(s)$ and $s \in(0,1)$, the domestic firm would choose to file in the venue that yields the higher license whether by settlement or adjudication. Some imports occur, but the chosen venue has lower imports.

Even our relatively simple model can explain the important and seemingly puzzling fact that the courts are commonly selected by plaintiff firms, despite the apparent advantage conferred on domestic firms by the import prohibition remedy used by the ITC. ITC filings are favored by low levels of product differentiation and low-value patents. For high levels of product differentiation and fairly high-value patents, the court is preferred, and for very high value patents, the domestic firm is indifferent between the two venues.

In cases with relatively low innovation value or not much product differentiation, the royalty negotiated in ITC cases may exceed the cost-reducing value of the innovation. In such cases, the foreign firm would be better off foregoing use of the innovation and just producing at marginal cost $c$ if it could make that change at sufficiently low cost. The potential for such an outcome may increase the incentive for the domestic firm to file in court. However, this possibility is excluded by our assumption that the innovation is sunk over the relevant period.

\section{Extensions and Generalizations}

\subsection{Fixed License Fees}

Suppose that the firms bargain over a fixed license fee $F$ (as, for example, in Hylton and Zhang, 2017) instead of a royalty. If imports are not excluded, the two firms operate at the same marginal cost, $c-v$, and, from (6) and (5), earn the same variable profit $\pi(0)=\pi^{\mathrm{f}}(0)=m^{2} /(2+$ $s)^{2}$. For a case filed at the ITC, letting $\pi^{\mathrm{M}}=m^{2} / 4$ represent the domestic firm's monopoly profit, the Nash product is $\mathrm{B}^{\mathrm{IF}}(0) \equiv\left(\pi(0)+F-\pi^{\mathrm{M}}\right)\left(\pi^{\mathrm{f}}(0)-F\right)$. Maximization of $\mathrm{B}^{\mathrm{IF}}(0)$ yields $F^{\mathrm{I}}=\pi^{\mathrm{M}} / 2$ $=m^{2} / 8$. The two firms agree to a settlement in the ITC if and only if $\pi^{\mathrm{f}}(0)-F^{\mathrm{I}}>0$, which 
requires that products be sufficient differentiated that $s<0.828$. If $s \geq 0.828$, which includes homogenous products, the ITC imposes an injunction that excludes the infringing imports.

If the case is filed in court, legal adjudication gives rise to royalty of $v$. Provided $v$ is not prohibitive $\left(v<r^{\mathrm{P}}(\mathrm{s})\right)$, the Nash product is $\mathrm{B}^{\mathrm{CF}}(0) \equiv(\pi(0)+F-\pi(v))\left(\pi^{\mathrm{f}}(0)-F-\pi^{\mathrm{f}}(v)\right)$. The firms settle at the Nash bargaining solution, $F^{\mathrm{C}}=\left(\pi(v)-\pi^{\mathrm{f}}(v)\right) / 2$, if and only if

$$
\pi^{\mathrm{f}}(0)-F^{C}-\pi^{\mathrm{f}}(v) \equiv \pi^{\mathrm{f}}(0)-\left(\pi(v)+\pi^{\mathrm{f}}(v)\right) / 2>0
$$

If the products are highly differentiated, there tends to be a settlement because fixed fees are a more efficient way to collect revenue. For sufficiently similar products, a reduction in imports raises the average profit of the two firms making (14) negative, so a royalty of $v$ is the outcome.

With respect to the domestic firm's choice of venue, we find that the court tends to be favored if products are highly differentiated and the value of innovation is large. ${ }^{5}$ Details differ, but these are the same characteristics that favored a court rather than an ITC filing when a royalty was the bargaining instrument. Despite the generality of this result, the fact that a settlement based on a fixed fee provides no protection from imports and therefore has no effect on domestic production remains an important difference between the two instruments for settling international IP disputes.

\subsection{The Default Royalty}

We have assumed that the default royalty in court is the value of the innovation. This is consistent with our reading of the case record. The most important U.S. legal precedent in this area is Georgia-Pacific Corp. v. United States Plywood Corp (1970), which sets out various principles for courts to consider in royalty determination in patent infringement cases. The major principles are "the advantages of the patent property over the old modes [of production]", the "realizable profit that should be credited to the invention", and a hypothetical negotiation "if both [firms] had been reasonably and voluntarily trying to reach an agreement". While the effect of

\footnotetext{
${ }^{5}$ For independent products, it follows from (14) that $\pi(0)-\left(\pi(v)+\pi^{\mathrm{f}}(v)\right) / 2=v^{2} / 8>0$. The parties settle at $F^{\mathrm{C}}=m^{2} / 8+(a-c)(2 v-(a-\mathrm{c})) / 8$ in court, which exceeds $F^{\mathrm{I}}=m^{2} / 8$ from an ITC settlement if $v>(a-c) / 2$. For homogeneous products, $\pi(0)-\left(\pi(v)+\pi^{\mathrm{f}}(v)\right) / 2=-v(a-c) / 18<0$, so the court imposes $v$, but the domestic firm prefers an ITC injunction preventing imports.
} 
these principles can be modelled in different ways, are all consistent with a default royalty of $v$ for plausible model specifications.

One notable feature of our analysis (see Proposition 3) is that for innovations with a sufficiently high value, the domestic firm's profit-maximizing royalty, $r^{*}$, is less than $v$ so both firms prefer a lower royalty. Legal precedent and concerns about deterrence of patent infringement might cause courts to impose a royalty of $v$ even in such cases. However, it is interesting to consider an alternative in which the default royalty is the minimum of $v$ and $r *$. This change would rule out any settlements in court. If $v \leq r^{*}(s)$, then the domestic firm would continue to prefer a court adjudication of $v$ rather than a settlement as shown in Proposition 6(i) and if $v>r^{*}(s)$, the domestic firm would enjoy its profit-maximizing royalty. Since the negotiated royalty, $r^{\mathrm{I}}(s)$, for an ITC case is less than $r^{*}(s)$ (Proposition 4(ii)), it follows that if $v>$ $r^{*}(s)$, the domestic firm will choose to file in court. In this case, we have $r^{\mathrm{I}}(s)<r^{*}(s)=r^{\mathrm{C}}(s)<v$ so the condition, $r^{\mathrm{I}}(s)<v$, in Proposition 8 under which the court provides more import protection still applies.

\subsection{Other Extensions}

Much of the literature on patent licensing emphasizes the role of uncertainty. Patents may be ruled invalid and, even for valid patents, there is often uncertainty over whether infringement will be found by the ITC or the court and, for court cases, over the size of the default royalty. If the firms are risk neutral and symmetrically informed, we can simply interpret the payoffs as expected values and the analysis is essentially unchanged. However, if there are important informational asymmetries or if the firms are risk averse, then our analysis would be more significantly affected.

We also abstract from legal costs, including the cost of filing a claim, the cost of litigating a case in court or before the ITC, and negotiation costs. Filing costs would be sunk costs in the context of our model and would have no effect. To the extent that litigation costs exceed negotiation costs, the effect would be to shift the outcome in the direction of settlements. Such costs would not otherwise affect our analysis.

Our model does not address the decision of the foreign firm to infringe the domestic firm's patent, but it is nevertheless interesting to determine when such patent infringement is or 
is not profitable for the foreign firm. For almost all incremental values of $v$ (i.e for $v \leq 0.9559(a-$ $c)$ ), Proposition 3 shows that $v<r^{*}(s)$ so, from Proposition 6, the outcome in court is an adjudicated royalty of $v$. Consequently, the foreign firm will typically gain no benefit from infringement of incremental innovations for cases filed in court and, from Proposition 5, will suffer a net loss for a broad range of cases filed at the ITC.

But why would the foreign firm choose to infringe if it anticipates a possible reduction in profits? The most obvious answer is based on uncertainty at a stage before our formal model begins. Specifically, the foreign firm may not know if its chosen production process involves infringement and may be uncertain as to whether a domestic firm will file a claim. Therefore, the foreign firm's decision over its production process could have a positive expected value, even if it has some probability of leading to profit-reducing litigation. Our model starts after the

resolution of such uncertainty and focuses on those cases in which infringement has occurred and a case is filed.

For intermediate or drastic innovations $(v \geq a-c)$, Proposition 3 has shown that $v>r^{*}(s)$, so from Proposition 6, the firms settle in court at a royalty that is less than $r^{*}(s)$ and $v$. As this last result also applies for cases filed at the ITC (Proposition 5), it is notable that for intermediate or drastic innovations there is always a negotiated settlement and the resulting royalty is less than the value of the innovation. The foreign firm therefore obtains a net benefit from infringement of intermediate or drastic innovations whether the case is filed in court or in the ITC. For high value innovations, the strong incentive for the domestic firm to settle at a royalty below the value of the innovation suggests that the existing IP protection available through the ITC or the courts may not be very effective as a deterrent.

\section{Concluding Remarks}

This paper draws attention to several important features of IP litigation applying to U.S. imports. First, cases alleging infringement by imports may be filed either in district court or in the International Trade Commission (ITC) and both venues are commonly used. Second, the ITC normally uses injunctive relief (imports are excluded from the domestic market) whereas the courts normally use fee-based relief (imports pay a royalty). Third, a majority of cases filed in both venues are settled through negotiation between the parties before final legal adjudication. 
We provide a model of IP litigation that addresses these institutional features. With homogenous products, the ITC provides more protection from infringing imports than the court for incremental innovations and provides the same protection for intermediate or drastic innovations. Thus, the homogenous products case is consistent with the standard intuition expressed in much of the legal literature.

When products are differentiated, we show that for a broad range of higher-value innovations, the standard intuition is overturned. For these cases, an ITC filing provides less protection from infringing imports than a filing in court. For any level of product differentiation, the domestic firm's profit with a suitably chosen royalty exceeds the monopoly profit it would earn from an ITC injunction. Consequently, the domestic firm is motivated to avoid an ITC injunction by negotiating a settlement with the foreign firm. For drastic innovations and for higher value incremental innovations with sufficient product differentiation, the domestic firm's position in Nash bargaining at the ITC is weakened to the point that the negotiated royalty is lower and imports are higher than if the case had been filed in court.

Our model makes several important simplifications to make the underlying principles clear. Relaxing these simplifications suggests natural areas of extension or generalization. In addition to the extensions discussed in Section 8, we could also consider alternative demand and market structures. While such extensions are potentially interesting, we believe that they would not eliminate the primary economic forces identified in our model. Specifically, the role of product differentiation and the role of innovation size should be robust to most reasonable directions of generalization.

Finally, the incentives identified here may apply in a much wider range of contexts, not just to the enforcement of international IP claims. The general question as to the effects of injunctive relief as opposed to fee-based relief for firms in an international trading environment could be important for the design of other policies, such as environmental policy or competition policy. We believe that our paper provides at least an interesting first step in a general comparison of injunctive and fee-based relief for firms adversely affected by the actions of foreign rivals. 


\section{Appendix A: Proofs of Propositions}

Proposition 2: The domestic firm's profit-maximizing royalty

i) For any given $s \in(0,1)$, domestic profit is maximized at a unique royalty, $r^{*}(s)$, that exceeds the level that maximizes royalty revenue, but does not prevent imports: $r^{\mathrm{R}}(s)<r^{*}(s)<r^{\mathrm{P}}(s)$.

ii) The profit-maximizing royalty, $r^{*}(s)$ for $s \in(0,1)$, approaches $m / 2$ as $s$ approaches either limit ( 0 or 1 ) and reaches a unique minimum at an interior value of $s$, denoted $s^{\theta}$.

Proof: i) To maximize $\pi(r)$ for $r \leq r^{\mathrm{P}}(s)$, we first use (5) to obtain

$$
x^{\prime}(r)=s /\left(4-s^{2}\right)>0 \text { and } y^{\prime}(r)=-2 /\left(4-s^{2}\right)<0
$$

Expanding $\pi^{\prime}(r)=2 x(r) x^{\prime}(r)+y(r)+r y^{\prime}(r)$ from (6), using (A1) and (5), it can be shown that

$$
\pi^{\prime}(r)=\left[\left(4+2 s-s^{2}\right)(2-s) m-2 r\left(8-3 s^{2}\right)\right] /\left(4-s^{2}\right)^{2}
$$

where $\pi^{\prime \prime}(r)=-2\left(8-3 s^{2}\right) /\left(4-s^{2}\right)^{2}<0$. From (A2) and $r^{\mathrm{P}}(s)=(2-s) m / 2$ (see (7)) we obtain

$$
\pi^{\prime}\left(r^{\mathrm{P}}(s)\right)=-2\left(2-s-s^{2}\right)(2-s) m /\left(4-s^{2}\right)^{2}
$$

It follows from (A3) that $\pi^{\prime}\left(r^{\mathrm{P}}(s)\right)<0$ for $s \in(0,1)$ and hence $r^{*}(s)<r^{\mathrm{P}}(s)$. Setting $\pi^{\prime}\left(r^{*}\right)=0$ in (A2), we obtain

$$
r^{*}(s)=\left(4+2 s-s^{2}\right)(2-s) m / 2\left(8-3 s^{2}\right)
$$

Maximizing $\mathrm{R}=r \mathrm{y}(r), r^{\mathrm{R}}(s)$ satisfies $y(r)+r y^{\prime}(r)=0$, which, using (5) and (A1), implies

$$
r^{\mathrm{R}}(s)=(2-s) m / 4
$$

Comparing (A5) with (A4), it follows that $r^{\mathrm{R}}(s)<r^{*}(s)<r^{\mathrm{P}}(s)$ for $s \in(0,1)$.

ii) We have $r^{*}(1)=r^{\mathrm{P}}(1)=m / 2$ from (8) and $r^{*}(0)=m / 2$ from (A4). Using the continuity of $r^{*}(s)$ for $s \in[0,1]$, it follows that for $s \in(0,1), r^{*}(s)$ approaches $m / 2$ as $s$ approaches 1 or 0 . To find the value of s that minimizes $r^{*}(s)$, we express (A4) as $r^{*}(s)=u(2-s) m / 2\left(8-3 s^{2}\right)$ where $u \equiv 4+$ $2 s-s^{2}$ to obtain $\mathrm{d} r *(s) / \mathrm{d} s=\left[\left(8-3 s^{2}\right)(2(1-s)(2-s)-u)+6 s u(2-s)\right] m / 2\left(8-3 s^{2}\right)^{2}$, which reduces to:

$$
\mathrm{d} r^{*}(s) / \mathrm{d} s=s\left[-16+24 s-3 s^{3}\right] m / 2\left(8-3 s^{2}\right)^{2}
$$

We can express (A6) as $\mathrm{d} r *(s) / \mathrm{d} s=3 s(s-0.71173)(s+3.12)(2.405-s) m / 2\left(8-3 s^{2}\right)^{2}$, which implies that the unique solution to $\mathrm{d} r^{*}(s) / \mathrm{d} s=0$ for $s \in(0,1)$ is $\mathrm{s}^{\theta}=0.71173$. Since $\mathrm{d}^{2} r^{*}\left(s^{\theta}\right) /(\mathrm{d} s)^{2}$ 
$=3 s^{\theta} \mathrm{m} / 2\left(8-3 s^{2}\right)^{2}>0, r^{*}\left(s^{\theta}\right)$ is the unique minimum of $r^{*}(s)$ for $s \in(0,1)$.

Proposition 3: Innovation value and the domestic firm's profit-maximizing royalty

With differentiated products:

i) If the innovation is incremental $(v<a-c)$, the domestic firm's profit-maximizing royalty equals or exceeds the value of the innovation $\left(r^{*}(s) \geq v\right)$ for almost all values of $v$, specifically for $v \leq 0.9559(a-c)$. If $0.9559(a-c)<v<a-c$, then the comparison between $r^{*}(s)$ and $v$ depends on $s$ and $v$.

ii) If the innovation is intermediate $(v=a-c)$ or drastic $(v>a-c)$, the domestic firm's profit maximizing royalty is always below the value $v$ of the innovation $\left(r^{*}(s)<v\right)$.

Proof: i) From the proof of Proposition 2(ii), the unique minimum of $r^{*}(s)$ for $s \in(0,1)$ is at $s^{\theta}=$ 0.7117 and, from (A4), we obtain $r^{*}\left(s^{\theta}\right)=0.48873 m$. Since $r^{*}(s) \geq r^{*}\left(s^{\theta}\right)$ for all $s \in(0,1)$, a sufficient condition for $r^{*}(s) \geq v$ is $r^{*}\left(s^{\theta}\right) \geq v$. Using $m \equiv a-c+v$, we obtain $r^{*}\left(s^{\theta}\right) \geq v$ for $v \leq$ $0.9559(a-c)$. If $0.9559(a-c)<v<a-c$, then $v>r^{*}\left(s^{\theta}\right)$, so $v$ must equal $r^{*}(s)$ at two values of $s \in(0,1)$. The comparison then depends on particular values of $s$ and $v$.

ii) For intermediate or drastic innovations, it follows from $v \geq a-c$ that $v \geq m / 2$. Since $r^{*}(s)<$ $m / 2$ for $s \in(0,1)$ (Proposition 2(ii)), we obtain $v>r^{*}(s)$ for $s \in(0,1)$.

Lemma 1: Assume $s \in(0,1)$. If $r \in\left[0, r^{*}(s)\right)$, the Nash product for an ITC case is strictly concave in $r$ :

$$
\mathrm{d}^{2} \mathrm{~B}^{\mathrm{I}}(r) /(\mathrm{d} r)^{2}=-12 \mathrm{y}(r) \pi^{\prime}(r) /\left(4-s^{2}\right)<0
$$

If $r \in\left(r^{*}(s), \mathrm{r}^{\mathrm{P}}(s)\right], \mathrm{B}^{\mathrm{I}}(r)$ is strictly convex in $r$.

Proof: From $\mathrm{B}^{\mathrm{I}}(r) \equiv\left(\pi(r)-\pi\left(r^{\mathrm{P}}(s)\right) \pi^{\mathrm{f}}(r)\right.$ as in (10), we obtain

$$
\mathrm{dB}^{\mathrm{I}}(r) / \mathrm{d} r=\left[\pi(r)-\pi\left(r^{\mathrm{P}}(s)\right)\right] \pi^{\mathrm{f}}(r)+\pi^{\mathrm{f}}(r) \pi^{\prime}(r)
$$

Examining the terms in (A8), it follows from $\pi^{\mathrm{f}}(r)=(\mathrm{y}(r))^{2}$ (see (6)) and (A1) that

$$
\pi^{\mathrm{f}}(r)=-4 \mathrm{y}(r) /\left(4-s^{2}\right)
$$

From (6) and (5), we have $\pi(r)-\pi\left(r^{\mathrm{P}}(s)\right)=(x(r))^{2}-(m / 2)^{2}+r y(r)$. Manipulating (5), we obtain $x(r)=(m-s y(r)) / 2$, which implies $(x(r))^{2}-(m / 2)^{2}=-s y(r)(x(r)+m / 2) / 2$. Substituting $x(r)$ from (5), we can show that $(x(r))^{2}-(m / 2)^{2}=-s y(r)[(4+s)(2-s) m+2 s r] / 4\left(4-s^{2}\right)$ and hence: 


$$
\pi(r)-\pi\left(r^{\mathrm{P}}(s)\right)=-y(r)\left[s(4+s)(2-s) m-2 r\left(8-3 s^{2}\right)\right] / 4\left(4-s^{2}\right)
$$

Using $\pi^{\prime}\left(r^{\mathrm{P}}(s)\right)$ from (A3) and $\pi^{\prime}(r)$ from (A2), (A10) can be expressed as

$$
\pi(r)-\pi\left(r^{\mathrm{P}}(s)\right)=-\left(4-s^{2}\right) y(r)\left[\pi^{\prime}(r)+\pi^{\prime}\left(r^{\mathrm{P}}(s)\right)\right] / 4
$$

Using (A11), $\pi^{\mathrm{f}}(r)=-4 \mathrm{y}(r) /\left(4-s^{2}\right)$ and $\pi^{\mathrm{f} \prime}(\mathrm{r})=8 /\left(4-\mathrm{s}^{2}\right)^{2}$ from (A9), (A8) can be expressed as

$$
\mathrm{dB}^{\mathrm{I}}(r) / \mathrm{d} r=(y(r))^{2}\left[2 \pi^{\prime}(r)+\pi^{\prime}\left(r^{\mathrm{P}}(s)\right)\right]
$$

From (A2) and (A3), a useful relationship is:

$$
\pi^{\prime}(r)=\pi^{\prime}\left(r^{\mathrm{P}}(s)\right)+\mathrm{y}(r)\left(8-3 s^{2}\right) /\left(4-s^{2}\right)
$$

From (A12), using $\pi^{\prime \prime}(r)=-2\left(8-3 s^{2}\right) /\left(4-s^{2}\right)^{2}$ and (A13), we obtain $\mathrm{d}^{2} \mathrm{~B}^{\mathrm{I}}(r) /(\mathrm{d} r)^{2}=-$

$12 \mathrm{y}(r) \pi^{\prime}(r) /\left(4-s^{2}\right)$ which is (A7). For $\mathrm{r} \in\left[0, r^{*}(s)\right)$, using $\pi^{\prime \prime}(r)<0$ and $r^{*}(s)<r^{\mathrm{P}}(s)$ for $s \in(0,1)$, we have $\pi^{\prime}(r)>0$ and $y(r)>0$ and hence $\mathrm{d}^{2} \mathrm{~B}^{\mathrm{I}}(r) /(\mathrm{d} r)^{2}<0$. If $\mathrm{r} \in\left(r^{*}(s), \mathrm{r}^{\mathrm{P}}(s)\right)$, then $\pi^{\prime}(r)<0$ and $\mathrm{d}^{2} \mathrm{~B}^{\mathrm{I}}(r) /(\mathrm{d} r)^{2}>0$.

\section{Proposition 4: Negotiated settlements at the ITC:}

For ITC cases with differentiated products and Nash bargaining by firms:

i) There is always a settlement with some imports. The negotiated royalty is unique and is given by $r^{\mathrm{I}}(s) \equiv(2+3 s)(2-s) m / 2\left(8-3 s^{2}\right)$.

ii) The negotiated royalty is less than the domestic profit-maximizing royalty: $r^{\mathrm{I}}(s)<\mathrm{r}^{*}(s)$

iii) Greater product differentiation reduces the negotiated royalty and increases imports.

Proof: i) We maximize $\mathrm{B}^{\mathrm{I}}(r) \equiv\left(\pi(r)-\pi\left(r^{\mathrm{P}}(s)\right) \pi^{\mathrm{f}}(r)\right.$ from (10) subject to $0 \leq r \leq r^{\mathrm{P}}(s)$ to obtain the Nash bargaining solution, $r^{\mathrm{I}}(s)$. From $\mathrm{d}\left(\mathrm{B}^{\mathrm{I}}\left(r^{\mathrm{P}}(s)\right) / \mathrm{d} s=0\right.$ from $(\mathrm{A} 8)$ and $\mathrm{d}^{2} \mathrm{~B}^{\mathrm{I}}\left(r^{\mathrm{P}}(s)\right) /(\mathrm{d} r)^{2}>0$ from (A7) due to $r^{*}(s)<r^{\mathrm{P}}(s)$ for $s \in(0,1)$ (Proposition 2(ii)), $\mathrm{B}^{\mathrm{I}}(r)$ is minimized at $r=r^{\mathrm{P}}(s)$. Thus, the constraint $r \leq r^{\mathrm{P}}(s)$ is not binding and from (A12), using (A2) and (A3), $r=r^{\mathrm{I}}(s)$ satisfies:

$$
\mathrm{dB}^{\mathrm{I}}(r) / \mathrm{d} r=2(y(r))^{2}\left\{(2+3 s)(2-s) m-2 r\left(8-3 s^{2}\right)\right\} /\left(4-s^{2}\right)^{2}=0
$$

Since $y(r)>0$ from $r<r^{\mathrm{P}}(s)$, (A14) implies that:

$$
r^{\mathrm{I}}(s) \equiv(2+3 s)(2-s) m / 2\left(8-3 s^{2}\right)>0
$$

It follows from $\mathrm{B}^{\mathrm{I}}\left(r^{\mathrm{I}}(s)\right)>\mathrm{B}^{\mathrm{I}}\left(r^{\mathrm{P}}(s)\right)=0$ that the firms always settle and from $r^{\mathrm{I}}(s)<r^{\mathrm{P}}(s)$ that there are always some imports. 
ii) From (A4) and (A15), we obtain $r^{*}(s)-r^{\mathrm{I}}(s)=\left(2-s-s^{2}\right)(2-s) m / 2\left(8-3 s^{2}\right)>0$ for $s \in(0,1)$.

From the strict concavity of $\mathrm{B}^{\mathrm{I}}(r)$ for $r \in\left[0, r^{*}(s)\right)$ and $s \in(0,1)$ (Lemma 1$), r^{\mathrm{I}}(\mathrm{s})$ is unique.

iii) From (A15), we can show $\mathrm{d} r^{\mathrm{I}}(s) / \mathrm{d} s=2\left(8-6 s+3 s^{2}\right) m /\left(8-3 s^{2}\right)^{2}>0$. Using $\partial y / \partial r<0$ and $\partial y / \partial s<0$ from (5), we obtain $\mathrm{d} y / \mathrm{d} s<0$, so a reduction in $s$ increases imports.

Proposition 5: Royalties and the value of innovation for ITC cases

For ITC cases with differentiated products:

i) An increase in the innovation's value $v$ increases the negotiated royalty, $r^{\mathrm{I}}(s)$, but by less than the increase in $v: 0<\partial r^{\mathrm{I}}(s ; v) / \partial v<1$.

ii) For small incremental innovations defined by $v \leq(a-c) / 3$, the negotiated royalty, $r^{\mathrm{I}}(s)$, strictly exceeds the value of the innovation $\left(r^{\mathrm{I}}(s)>v\right)$.

iii) For larger incremental innovations $((a-c) / 3<v<a-c)$, there exists a critical value of $s \equiv$ $\breve{s}(v) \in(0,1)$ satisfying $r^{\mathrm{I}}(\breve{s})=v$, such that $r^{\mathrm{I}}(s)<v$ if and only if the products are sufficiently differentiated (s is sufficiently small) that $s \in(0, \breve{s}(v))$. As $v$ becomes larger, $\check{s}(v)$ increases, expanding the range of cases for which $r^{\mathrm{I}}(s)<v$ to include products that are more similar.

iv) For intermediate or drastic innovations $(v \geq a-c)$, the negotiated royalty is strictly below the value of the innovation $\left(r^{\mathrm{I}}(s)<v\right)$.

Proof: i) From $r^{\mathrm{I}}(s ; v) \equiv\left(4+4 s-3 s^{2}\right) m / 2\left(8-3 s^{2}\right)$ (see (A15)) and $m \equiv a-c+v$, we obtain $\partial\left(r^{\mathrm{I}}(s ; v) / \partial v=\left(4+4 s-3 s^{2}\right) / 2\left(8-3 s^{2}\right)>0\right.$ and $1-\partial\left(r^{\mathrm{I}}(s ; v) / \partial v=\left(12-4 s-3 s^{2}\right) / 2\left(8-3 s^{2}\right)>0\right.$.

ii) From (A15), we obtain

$$
r^{\mathrm{I}}(s)-v=\left[\left(4+4 s-3 s^{2}\right)(a-c-3 v)+2 s(8-3 s) v\right] / 2\left(8-3 s^{2}\right)
$$

From (A16), $r^{\mathrm{I}}(s)-v>0$ for $v \leq(a-c) / 3$.

iii) For $(a-c) / 3<v<a-c$, letting $s=\check{s} \in(0,1)$ satisfy $r^{\mathrm{I}}(s ; v)=v$, it follows from (A16) that

$$
3(a-c-v) \check{s}^{2}-4 m \check{s}+4(3 v-(a-c))=0
$$

From (A17), $\check{s}=0$ if $v=(a-c) / 3$ and $\check{s}=1$ if $v=a-c$, then $\check{s}=1$. Totally differentiating $r^{\mathrm{I}}(\check{s} ; v)$ $=v$ and using $\left.\partial r^{\mathrm{I}}(\check{s} ; v) / \partial v\right)<1$ from Part i and $\mathrm{d} r^{\mathrm{I}}(s) / \mathrm{d} s>0$ from Proposition 4 , we obtain $\mathrm{d} \check{s} / \mathrm{d} v=$ $\left.\left(1-\partial r^{\mathrm{I}}(\check{s} ; v) / \partial v\right)\right) / \mathrm{d} r^{\mathrm{I}}(\check{s}) / \mathrm{d} s>0$. Hence $\check{s}=\check{s}(v) \in(0,1)$ if and only if $(a-c) / 3<v<a-c$. From $r^{\mathrm{I}}(\breve{s})=v$ and $\mathrm{d} r^{\mathrm{I}}(s) / \mathrm{d} s>0$ (Proposition 4), it also follows that $r^{\mathrm{I}}(s)<v$ for $v \in((a-c) / 3, a-c)$ if and only if $s \in(0, \check{s}(v))$. Since $\mathrm{d} \check{s} / \mathrm{d} v>0$, an increase in $v \in((a-c) / 3, a-c)$ expands the range of 
$s$ for which $r^{\mathrm{I}}(s)<v$ to include more substitutable products.

For an incremental innovation $(v<a-c)$, solving the quadratic function, (A17), for $\check{s}$, we obtain a unique solution given by:

$$
\check{s}=\check{s}(v)=2\left\{m-\left[m^{2}-3(a-c-v)(3 v-(a-c)]^{1 / 2}\right\} / 3(a-c-v)\right.
$$

There is a second, higher value, of $s$ satisfying (A17), but this solution is ruled out because it exceeds $2 m / 3(a-c-v)$, which, by itself, exceeds 1 for all $v>(a-c) / 5$.

iv) For $v \geq a-c$ and for $s \in(0,1)$, we have $r^{\mathrm{I}}(s)<r^{*}(s)$ from Proposition 4(i) and $r^{*}(s)<v$ from Proposition 3(ii), which implies $r^{\mathrm{I}}(s)<r^{*}(s)<v$.

Lemma 2: Assume $s \in(0,1)$. If $r \in[0, v]$ where $v<r^{*}(s)$ or if $r \in\left[0, r^{*}(s)\right]$ where $r^{*}(s)<v<$ $r^{\mathrm{P}}(s)$, then the Nash product for court cases, $\mathrm{B}^{\mathrm{C}}(r)$, is strictly concave in $r$ :

$$
\mathrm{d}^{2} \mathrm{~B}^{\mathrm{C}}(r) /(\mathrm{d} r)^{2}=-4\left[3 \mathrm{y}(r) \pi^{\prime}(r)-y(v) \pi^{\prime}(v)\right] /\left(4-s^{2}\right)<0
$$

Proof: From $\mathrm{B}^{\mathrm{C}}(r)=(\pi(r)-\pi(v))\left(\pi^{\mathrm{f}}(r)-\pi^{\mathrm{f}}(v)\right)$ for $v<r^{\mathrm{P}}(s)$ and $\mathrm{B}^{\mathrm{I}}(r)=\left(\pi(r)-\pi\left(r^{\mathrm{P}}(s)\right) \pi^{\mathrm{f}}(r)\right.$ (see (12) and (10)), we obtain $\mathrm{B}^{\mathrm{C}}(r)=\mathrm{B}^{\mathrm{I}}(r)+\Phi(r)$ where $\Phi(r) \equiv-(\pi(r)-\pi(v)) \pi^{\mathrm{f}}(v)-(\pi(v)-$ $\left.\pi\left(r^{\mathrm{P}}(s)\right)\right) \pi^{\mathrm{f}}(r)$. Hence,

$$
\mathrm{dB}^{\mathrm{C}}(r) / \mathrm{d} r=\mathrm{dB}^{\mathrm{I}}(r) / \mathrm{d} r+\Phi^{\prime}(r)
$$

where $\Phi^{\prime}(r)=-\pi^{\prime}(r) \pi^{\mathrm{f}}(v)-\left(\pi(v)-\pi\left(r^{\mathrm{P}}(s)\right) \pi^{\mathrm{f}^{\prime} \prime}(r)\right.$. From (A20) and $\mathrm{d}^{2} \mathrm{~B}^{\mathrm{I}}(r) /(\mathrm{d} r)^{2}$ as in (A7), we obtain $\mathrm{d}^{2} \mathrm{~B}^{\mathrm{C}}(r) /(\mathrm{d} r)^{2}=-12 \mathrm{y}(r) \pi^{\prime}(r) /\left(4-s^{2}\right)+\Phi^{\prime \prime}(r)$ where $\Phi^{\prime \prime}(r)=-\pi^{\mathrm{f}}(v) \pi^{\prime \prime}(r)-(\pi(v)-$ $\pi\left(r^{P}(s)\right) \pi^{\mathrm{f} \prime \prime}(r)$. Using $\pi(v)-\pi\left(r^{\mathrm{P}}(s)\right)$ from (A11), $\pi^{\prime \prime}(r)=-2\left(8-3 s^{2}\right) /\left(4-s^{2}\right)^{2}$ and $\pi^{\mathrm{f} \prime \prime}(r)=8 /(4-$ $\left.\mathrm{s}^{2}\right)^{2}$, we can show

$$
\Phi^{\prime \prime}(r)=2 \mathrm{y}(v)\left\{\mathrm{y}(v)\left(8-3 s^{2}\right) /\left(4-s^{2}\right)+\left[\pi^{\prime}(v)+\pi^{\prime}\left(r^{\mathrm{P}}(s)\right)\right]\right\} /\left(4-s^{2}\right)
$$

Substituting $\pi^{\prime}(v)=\pi^{\prime}\left(r^{\mathrm{P}}(s)\right)+\mathrm{y}(v)\left(8-3 s^{2}\right) /\left(4-s^{2}\right)$ from (A13) in (A21), we obtain $\Phi^{\prime \prime}(r)=$ $4 \mathrm{y}(v) \pi^{\prime}(v) /\left(4-s^{2}\right)$ and it follows that $\mathrm{d}^{2} \mathrm{~B}^{\mathrm{C}}(r) /(\mathrm{d} r)^{2}$ is as stated in (A19).

From $\pi^{\prime \prime}(r)<0$, we have $\pi^{\prime}(r) \geq 0$ for $r \leq r^{*}(s)$ and $\pi^{\prime}(v)<0$ for $v>r^{*}(s)$. If $r \in\left[0, r^{*}(s)\right]$ where $r^{*}(s)<v<r^{\mathrm{P}}(s)$, then, using $y(r)>0$, we obtain $\mathrm{d}^{2} \mathrm{~B}^{\mathrm{C}}(r) /(\mathrm{d} r)^{2}<0$ from (A19). If $r \in[0, v]$ and $v<r^{*}(s)$ then $\pi^{\prime}(v)>0$ and manipulating $(17 \mathrm{H})$, we obtain $\mathrm{d}^{2} \mathrm{~B}^{\mathrm{C}}(r) /(\mathrm{d} r)^{2}=-\left[4 y(r)\left(3 \pi^{\prime}(r)\right.\right.$ $\left.\left.\pi^{\prime}(v)\right)+\pi^{\prime}(v)(y(r)-y(v))\right]<0$. The sign follows from $\pi^{\prime}(r) \geq \pi^{\prime}(v)$ and $y(r) \geq y(v)$ for $r \in[0, v]$ due to $\pi^{\prime \prime}(r)<0$ and $y^{\prime}(r)<0$. 
Proposition 6: Settlement or adjudication in court when $v<r^{\mathrm{P}}(s)$.

For cases filed in court with differentiated products and $v<r^{\mathrm{P}}(s)$ :

i) If $v \leq r^{*}(s)$ the firms do not settle and the court adjudicates a royalty of $v$.

ii) If $v>r^{*}(s)$ there is a settlement. The firms negotiate a unique royalty, $r^{\mathrm{C}}(s)$, that exceeds zero and is less than the domestic profit-maximizing royalty: $0<r^{\mathrm{C}}(s)<r^{*}(s)$.

Proof: For $v<r^{\mathrm{P}}(s)$ and $s \in(0,1)$, we maximize $\mathrm{B}^{\mathrm{C}}(r) \equiv(\pi(r)-\pi(v))\left(\pi^{\mathrm{f}}(r)-\pi^{\mathrm{f}}(v)\right)$ from (12) subject to $0 \leq r \leq r^{\mathrm{P}}(s)$ to obtain the Nash bargaining solution, $r^{\mathrm{C}}(s)$. The constraint $r \leq r^{\mathrm{P}}(s)$ is not binding: if $r \in\left(v, r^{\mathrm{P}}(s)\right]$, then $\pi^{\mathrm{f}}(r)-\pi^{\mathrm{f}}(v)<0$ (see (A9)) and $\mathrm{B}^{\mathrm{C}}(r)<0$, whereas $\mathrm{B}^{\mathrm{C}}(v)=0$. Consequently, $r^{\mathrm{C}}(s)$ satisfies

$$
\mathrm{dB}^{\mathrm{C}}(r) / \mathrm{d} r=(\pi(r)-\pi(v)) \pi^{\mathrm{f}}(r)+\left(\pi^{\mathrm{f}}(r)-\pi^{\mathrm{f}}(v)\right) \pi^{\prime}(r)=0
$$

which is (13) of the text.

i) If $v \leq r^{*}(s)$, then using $\pi^{\prime \prime}(r)<0$, we obtain $\pi^{\prime}(r)>0$ and $\pi(r)-\pi(v)<0$ for $r \in[0, v)$. Using $\pi^{\mathrm{f}}(r)<0$ (see (A9)), we have $\pi^{\mathrm{f}}(r)-\pi^{\mathrm{f}}(v)>0$ and hence $\mathrm{dB}^{\mathrm{C}}(r) / \mathrm{d} r>0$ for $r \in[0, v)$ from (A22). Since $\mathrm{dB}^{\mathrm{C}}(v) / \mathrm{d} r=0$ from (A22), the unique maximum of $\mathrm{B}^{\mathrm{C}}(r)$ for $r \in[0, v]$ is at $r=v$ (the trivial solution). The domestic firm will not settle and the court imposes $r=v$.

ii) For $r^{*}(s)<v<r^{\mathrm{P}}(s)$, it follows from $\pi^{\prime}\left(r^{*}(s)\right)=0$ and $\pi^{\prime \prime}(r)<0$ that $\pi^{\prime}(v)<0$ and, from (A19), we obtain $\mathrm{d}^{2} \mathrm{~B}^{\mathrm{C}}(v) /(\mathrm{d} r)^{2}=-8 y(v) \pi^{\prime}(v) /\left(4-s^{2}\right)>0$. At $r=v$, we have $\mathrm{dB}^{\mathrm{C}}(v) / \mathrm{d} r=0$ from (A22), so $\mathrm{B}^{\mathrm{C}}(v)=0$ represents a minimum of $\mathrm{B}^{\mathrm{C}}(r)$ for $r \leq v$. The parties will choose to settle.

To show that there exists $r^{\mathrm{C}}(s) \in\left(0, r^{*}(\mathrm{~s})\right)$ that maximizes $\mathrm{B}^{\mathrm{C}}(r)$, we show that $\mathrm{dB}^{\mathrm{C}}(0) / \mathrm{d} r$ $>0$ and $\mathrm{dB}^{\mathrm{C}}\left(r^{*}(s)\right) / \mathrm{d} r<0$. From (A22), $\pi(0)-\pi(v)<0, \pi^{\mathrm{f}}(0)-\pi^{\mathrm{f}}(v)>0, \pi^{\mathrm{f}}(r)<0$ and $\pi^{\prime}(0)>0$, we have $\mathrm{dB}^{\mathrm{C}}(0) / \mathrm{d} r>0$. From (A22), using $\pi^{\prime}\left(r^{*}(s)\right)=0, \pi\left(r^{*}(s)\right)-\pi(v)>0$ and $\pi^{\mathrm{f \prime}}(r)<0$, we have $\mathrm{dB}^{\mathrm{C}}\left(r^{*}(s)\right) / \mathrm{d} r=\left(\pi\left(r^{*}(s)\right)-\pi(v)\right) \pi^{\mathrm{f} \prime}\left(r^{*}(\mathrm{~s})\right)<0$. From $\mathrm{d}^{2} \mathrm{~B}^{\mathrm{C}}(r) /(\mathrm{d} r)^{2}<0$ for $r \in\left[0, r^{*}(s)\right]$ where $r^{*}(s)<v<r^{\mathrm{P}}(s)$ (Lemma 2), $r^{\mathrm{C}}(s)$ satisfying (A22) is unique.

Proposition 7: Conditions for $v<r^{\mathrm{P}}(s)$

i) For differentiated products, a royalty of $v$ allows some imports $\left(v<r^{\mathrm{P}}(s)\right)$ if:

(a) the innovation is incremental or intermediate $(v \leq a-c)$;

(b) the innovation is drastic $(v>a-c)$ and $v \in(a-c, \gamma(a-c))$ where $\gamma \equiv(2-s) / s>1$. 
ii) In the limit as products become independent ( $s$ tends to zero), a royalty of $v$ can never prevent imports. As products become more substitutable, the range of values of $v$ for which there are imports is reduced and, in the limit as $s$ tends to 1 , there are no imports for $v \geq a-c$.

Proof: i) Using $r^{\mathrm{P}}(s)=(2-s) m / 2$ from (7) and $m \equiv a-c+v$ (see (3)), we obtain

$$
r^{\mathrm{P}}(s)-v=(2-s)(a-c-v) / 2+v(1-s)
$$

(a) From (A23), $r^{\mathrm{P}}(s)-v>0$ if $v \leq a-c$. (b) Rearranging (A23), we obtain $r^{\mathrm{P}}(s)-v=[(2-s)(a$ $-c)-s v] / 2$. Letting $\gamma \equiv(2-s) / s$ for $s \neq 0$, it follows that $r^{\mathrm{P}}(s)-v>0$ if and only if $v<\gamma(a-c)$, where $s<1$ implies $\gamma>1$. If the innovation is drastic $(v>a-c)$, then $v<r^{\mathrm{P}}(s)$ if and only if $v \in$ $(a-c, \gamma(a-c))$.

ii) Setting $s=0$ in (A23), we obtain $r^{\mathrm{P}}(0)-v=a-c>0$, which shows that in the limit as $s \rightarrow 0$ there are always some imports at $r=v$. From $\mathrm{d} \gamma / \mathrm{d} s=-2 / s^{2}<0$, an increase in $s$ reduces the range of $v \in(a-c, \gamma(a-c))$ for which $v<r^{\mathrm{P}}(s)$. From (A23), we obtain $r^{\mathrm{P}}(1)-v=(a-c-v) / 2 \leq 0$ for $v \geq a-c$, so in the limit as $s \rightarrow 1$, a royalty of $v$ is prohibitive for $v \geq a-c$.

Proposition 8: Does the ITC or the Court provide more import protection?

With differentiated products and $v<r^{\mathrm{P}}(s)$ :

i) The ITC provides more import protection than the court if $r^{\mathrm{I}}(s)>v$.

ii) The two venues provide equal import protection if $r^{\mathrm{I}}(s)=v$.

iii) The ITC provides less import protection than the court if the negotiated royalty for an ITC case is less than the cost-reducing value of the innovation: $r^{\mathrm{I}}(s)<v$.

Proof: i) If $r^{\mathrm{I}}(s)>v$, then $r^{\mathrm{I}}(s)>r^{\mathrm{C}}(s)$ due to $r^{\mathrm{C}}(s) \leq v$ when the default royalty is $v$. The ITC has the higher royalty, so from (5), it provides more import protection.

ii) To show that $r^{\mathrm{C}}(\mathrm{s})=r^{\mathrm{I}}(s)$ if $r^{\mathrm{I}}(s)=v$, the result follows immediately if $v \leq r^{*}(s)$, since then a royalty of $v$ is adjudicated in court (Proposition 6). The case $v>r^{*}(s)$ is not relevant since $r^{\mathrm{I}}(s)<$ $r^{*}(s)$ (Proposition 4) implies $r^{\mathrm{I}}(s) \neq v$.

iii) To show that import protection is lower at the ITC $\left(r^{\mathrm{I}}(s)<r^{\mathrm{C}}(s)\right)$ for $r^{\mathrm{I}}(s)<v$, we first consider $v \leq r^{*}(s)$. If $v \leq r^{*}(s)$, then $r^{\mathrm{C}}(s)=v$ due to court adjudication (Proposition 6), proving the result for $r^{\mathrm{I}}(s)<v \leq r^{*}(s)$. If $v>r^{*}(s)$, then $r^{\mathrm{C}}(s)<r^{*}(s)<v$ (Proposition 6) and $r^{\mathrm{I}}(s)<r^{*}(\mathrm{~s})<$ $v$ (Proposition 4). From the strict concavity of $\mathrm{B}^{\mathrm{C}}(r)$ for $r \in\left[0, r^{*}(s)\right]$ where $r^{*}(s)<v<r^{\mathrm{P}}(s)$ (Lemma 2), to prove $r^{\mathrm{I}}(s)<r^{\mathrm{C}}(s)$ for $r^{\mathrm{I}}(s)<v$, it remains to prove that $\mathrm{dB}^{\mathrm{C}}\left(r^{\mathrm{I}}(s)\right) / \mathrm{d} r>0$. 
From $\mathrm{dB}^{\mathrm{C}}(r) / \mathrm{d} r=\mathrm{dB}^{\mathrm{I}}(r) / \mathrm{d} r+\Phi^{\prime}(r)$ as in (A20), it follows, setting $\mathrm{dB}^{\mathrm{I}}(r) / \mathrm{d} r=0$, that $\mathrm{dB}^{\mathrm{C}}\left(r^{\mathrm{I}}(s)\right) / \mathrm{d} r=\Phi^{\prime}\left(r^{\mathrm{I}}\right)=-\left(\pi(v)-\pi\left(r^{\mathrm{P}}(s)\right) \pi^{\mathrm{f}^{\prime \prime}}\left(r^{\mathrm{I}}\right)-\pi^{\prime}\left(r^{\mathrm{I}}\right) \pi^{\mathrm{f}}(v)\right.$. Substituting $\pi^{\prime}\left(r^{\mathrm{I}}\right)=-\left[\pi\left(r^{I}\right)-\right.$ $\left.\pi\left(r^{\mathrm{P}}(s)\right)\right] \pi^{\mathrm{f}}\left(r^{I}\right) / \pi^{\mathrm{f}}\left(r^{\mathrm{I}}\right)$ (from $\mathrm{dB}^{\mathrm{I}}(r) / \mathrm{d} r=0$ and (A8)), and using $\pi^{\mathrm{f}}(r)=(y(r))^{2}$ and $\pi^{\mathrm{f}}(r)=-4 y(r) /(4$ $-s^{2}$ ) (from (A9)), we can show

$$
\mathrm{dB}^{\mathrm{C}}\left(r^{\mathrm{I}}(s)\right) / \mathrm{d} r=4\left[\left(\pi(v)-\pi\left(r^{\mathrm{P}}(s)\right)\left(y\left(r^{\mathrm{I}}\right)\right)^{2}-\left(\pi\left(r^{\mathrm{I}}\right)-\pi\left(r^{\mathrm{P}}(s)\right)(\mathrm{y}(v))^{2}\right] / y\left(r^{\mathrm{I}}\right)\left(4-s^{2}\right)\right.\right.
$$

Letting $\psi(r) \equiv 2 r\left(8-3 s^{2}\right)-s(4+s)(2-s) m$, it follows from (A10) that $\pi(r)-\pi\left(r^{\mathrm{P}}(s)\right)=$ $y(r) \psi(r) / 4\left(4-s^{2}\right)$, so (A24) can be expressed as:

$$
\mathrm{dB}^{\mathrm{C}}\left(r^{\mathrm{I}}(s)\right) / \mathrm{d} r=y(v)\left[\psi(v) y\left(r^{\mathrm{I}}(s)\right)-\psi\left(r^{\mathrm{I}}(s)\right) \mathrm{y}(v)\right] /\left(4-s^{2}\right)^{2}
$$

From (A25) using $\psi(v)-\psi(r)=2(v-r)\left(8-3 s^{2}\right)$ and $y(r)-y(v)=2(v-r) /\left(4-s^{2}\right)$, we obtain $\mathrm{dB}^{\mathrm{C}}\left(r^{\mathrm{I}}(s)\right) / \mathrm{d} r=2\left(v-r^{\mathrm{I}}(s)\right) y(v)\left[\psi\left(r^{\mathrm{I}}(s)\right)+\left(4-s^{2}\right) y\left(r^{\mathrm{I}}(s)\right)\left(8-3 s^{2}\right)\right] /\left(4-s^{2}\right)^{3}$ and hence

$$
\mathrm{dB}^{\mathrm{C}}\left(r^{\mathrm{I}}(s)\right) / \mathrm{d} r=8\left(v-r^{\mathrm{I}}(s)\right) \mathrm{y}(v)(2-s) m[2-s(1+s)] /\left(4-s^{2}\right)^{3}
$$

It follows from (A26), $s \in(0,1)$ and $y(v)>0$ for $v<r^{\mathrm{P}}(s)$ that if $r^{\mathrm{I}}(s)<v$ then $\mathrm{dB}^{\mathrm{C}}\left(r^{\mathrm{I}}(s)\right) / \mathrm{d} r>0$, which proves that $r^{\mathrm{I}}(s)<r^{\mathrm{C}}(s)$ for $r^{\mathrm{I}}(s)<r^{*}(\mathrm{~s})<v$ and hence proves the result.

Proposition 9: Innovation size and protection from imports by venue

With differentiated products:

i) For small incremental innovations $(v \leq(a-c) / 3)$, the ITC provides more protection from imports than the court. A royalty of $v$ is adjudicated by the court, whereas in the ITC, the firms settle at $r=r^{\mathrm{I}}(s)$ that strictly exceeds $v$.

ii) For larger incremental innovations $((a-c) / 3<v<a-c)$, the ITC provides less protection from imports than the court if and only if the products are sufficiently differentiated that $s<\check{s}(v)$ where $\breve{s}$ satisfies $r^{\mathrm{I}}(\check{\mathrm{s}}) \equiv v$. If $s<\breve{s}(v)$, firms settle on a royalty, $r^{\mathrm{I}}(s)$, in the ITC that is strictly less than $v$ and less than any royalty, $r^{\mathrm{C}}(s)$, negotiated in court. The higher is the value of $v$, the greater is the range of product differentiation for which the ITC provides less protection from imports than the court.

iii) For innovations that are intermediate or drastic but not so drastic that a royalty of $v$ is prohibitive $(v \in[a-c, \gamma(a-c))$ where $\gamma \equiv(2-s) / s>1)$, the ITC provides less protection from imports than the court. The firms settle on a royalty below $v$ in both venues, but the royalty is strictly lower in the ITC. 
iv) For very drastic innovations ( $v \geq r^{P}(s)$ ), the ITC and the court provide the same protection against imports. There is a settlement in both venues and Nash bargaining in the court and the ITC yield the same royalty giving rise to the same (positive) level of imports.

Proof: i) If $v \leq(a-c) / 3$, then $v<r^{*}(s)$ (Proposition 3(i)), which implies a royalty of $v$ adjudicated by the court (Proposition 6(i)). For ITC cases, the firms always settle (Proposition 4) at a royalty, $r^{\mathrm{I}}(s)$, that strictly exceeds $v$ (Proposition 5 ). Since a higher royalty reduces imports $\left(y^{\prime}(r)<0\right.$ from (A1)), the ITC provides more import protection than the court.

ii) If $(a-c) / 3<v<a-c$, then for ITC cases, the firms settle at $r^{\mathrm{I}}(s)<v$ if and only if $s<\breve{s}(v)$ where š satisfies $r^{\mathrm{I}}(\breve{\mathrm{s}}) \equiv v$ and $\check{s}^{\prime}(v)>0$ (Proposition 5(iii)). Since $r^{\mathrm{I}}(s)<r^{\mathrm{C}}(s)$ if and only if $r^{\mathrm{I}}(s)<$ $v$ (Proposition 8(iii)), the ITC provides less import protection than the court if and only if $s<$ $\breve{s}(v)$. The effect of a higher value of $v$ follows from dš/d $v>0$ (Proposition 5(iii)).

iii) If $v \geq a-c$ and $v<r^{\mathrm{P}}(s)$ then $v \in[a-c, \gamma(a-c))$ where $\gamma \equiv(2-s) / s>1$ (Proposition 7) and $r^{*}(s)<v$ for all $s \in(0,1)$ (Proposition 3(ii)). In court, the firms settle at $r=r^{\mathrm{C}}(s)<\mathrm{r}^{*}(\mathrm{~s})<v$ (Proposition 6(ii)). In the ITC, the firms also settle at $r=r^{\mathrm{I}}(\mathrm{s})<\mathrm{r}^{*}$ (s) $<v$ (Proposition 5(iv)), but since $r^{\mathrm{I}}(s)<v$ and $v<r^{\mathrm{P}}(s)$, we have $r^{\mathrm{I}}(s)<r^{\mathrm{C}}(s)$ (Proposition 8(iii)), which proves that the ITC provides less protection from imports than the court.

iv) If $v \geq r^{\mathrm{P}}(s)$, then adjudication in either venue excludes imports and, in court, the parties negotiate a royalty of the same value, $r=r^{\mathrm{I}}(s)$, that would be negotiated in the ITC (see section 6.3 of the text). It follows from $r^{\mathrm{I}}(s)<r^{*}(s)$ (Proposition $4(\mathrm{i})$ ) and $\mathrm{r}^{*}(s)<r^{\mathrm{P}}(s)$ for $s \in(0,1)$ (Proposition 2(i)) that $r^{\mathrm{I}}(s)<r^{\mathrm{P}}(s)$, so imports are strictly positive at the settlement.

Proposition 10: Choosing where to file

For $v<r^{P}(s)$ and $\mathrm{s} \in(0,1)$, the domestic firm would choose to file in the venue that yields the higher license whether by settlement or adjudication. Some imports occur, but the chosen venue has lower imports.

Proof: If $v<r^{P}(s)$, the royalty determined in the ITC or the court, whether by a settlement or adjudication, is less than $r^{*}(s)$ (Propositions 4(i) and (5)). From $\pi^{\prime \prime}(r)<0$, we have $\pi^{\prime}(r)>0$ for $r$ $<r^{*}(s)$ and hence the domestic firm will increase its profit by choosing the venue that results in the higher royalty. 


\section{References}

Aoki, Reiko, and Thomas J. Prusa, 1993. International standards for intellectual property protection and R \& D incentives. Journal of International Economics 35 (3-4), 251-273.

Arrow, Kenneth J., 1962. “Economic welfare and the allocation of resources to invention”, in Nelson, R. R. (ed.), The Rate and Direction of Inventive Activity: Economic and Social Factors, Princeton, NJ: Princeton University Press, pp. 609-25.

Blonigen, Bruce A. and Thomas J. Prusa (ed.), 2019. “Dumping and Antidumping Trade Protection,” Edward Elgar Publishing: 18064.

Bond, E.W., and K. Saggi, 2020. Patent protection in developing countries and global welfare: WTO obligations versus flexibilities. Journal of International Economics, 122:103281.

Brander, James A., 2007. "Intellectual property protection as strategic trade policy." Asia-Pacific Journal of Accounting \& Economics 14, (3): 195-217.

Brander, James A., and Barbara J. Spencer, 2021. "Patent Assertion Entities and the Courts: Injunctive or Fee-Based Relief?” International Review of Law and Economics 65 (March): 105974. doi: 10.1016/j.irle.2020.105974.

Chen, Yongmin, Jota Ishikawa, and Yu Zhihao, 2004. "Trade liberalization and strategic outsourcing." Journal of International Economics 63 (2): 419-436.

Co, Catherine Y., 2004. "How Valuable are the Patents Behind Section 337 Cases?." The World Economy 27, (4): 525-539.

Daughety, Andrew F., and Jennifer Reinganum, 2012. "Settlement.” in C.W. Sanchirico (ed) Encyclopedia of Law and Economics ( $2^{\text {nd }}$ ed.), Vol. 8: Procedural Law and Economics. Cheltenham: Edward Elgar: 386-471.

Gallaway, Michael P., Bruce A. Blonigen, and Joseph E. Flynn, 1999. "Welfare costs of the US antidumping and countervailing duty laws." Journal of International Economics 49, no. 2: 211244.

Hylton, Keith N., and Mengxi Zhang, 2017. "Optimal remedies for patent infringement." International Review of Law and Economics 52: 44-57.

Irwin, Douglas A., 2005. "The Rise of US Anti-dumping Activity in Historical Perspective." The World Economy 28, no. 5: 651-668.

Kamien, Morton.I., 1992. Patent licensing. Handbook of game theory with economic applications, 1, pp.331-354.

Kishimoto, Shin, 2020. The Welfare Effect of Bargaining Power in the Licensing of a Costreducing Technology. Journal of Economics, 129(2), pp.173-193. 
Kishimoto, Shin and Shigeo Muto, 2012. "Fee versus royalty policy in licensing through bargaining: An application of the Nash bargaining solution." Bulletin of Economic Research 64, no. 2: 293-304.

Maskus, Keith E., and Penubarti Mohan, 1995. "How trade-related are intellectual property rights?." Journal of International economics 39, no. 3: 227-248.

McCalman, Phillip, 2005. "Who enjoys 'TRIPs' abroad? An empirical analysis of intellectual property rights in the Uruguay round." Canadian Journal of Economics 38, no. 2: 574-603.

Mutti, John and Bernard Yeung, 1996. "Section 337 and the protection of intellectual property in the United States: The complainants and the impact." The Review of Economics and Statistics: 510-520.

Nash, John, 1953. "Two-person cooperative games." Econometrica: 21(1): 128-140.

Prusa, Thomas J., 1992. Why are so many antidumping petitions withdrawn? Journal of International Economics, 33(1-2), 1-20.

Qiu, Larry D., and H. Yu, 2010. Does the protection of foreign intellectual property rights stimulate innovation in the US?. Review of International Economics, 18(5), pp.882-895.

Rovengo, Laura, 2013. Trade protection and market power: evidence from US antidumping and countervailing duties. Review of World Economics, 149(3), 443-476.

Shapiro, Carl, 2010. "Injunctions, hold-up, and patent royalties." American Law and Economics Review 12, no. 2: 280-318. 